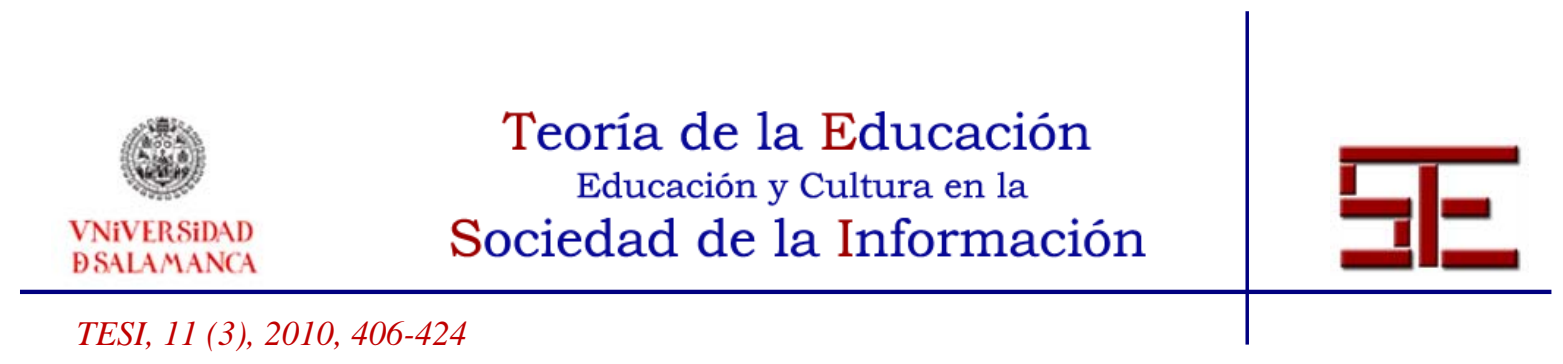

\title{
POLÍTICAS EDUCATIVAS PÚBLICAS EN COREA DEL SUR EN LA FORMACIÓN DE LA SOCIEDAD DE LA INFORMACIÓN
}

\section{Resumen:}

El objetivo de este artículo es estudiar y analizar las políticas educativas públicas de la Sociedad de la Información en Corea del Sur desde finales del siglo pasado hasta nuestros días. Ver la traducción de estas políticas en actuaciones concretas dentro del sistema educativo coreano y especialmente en la educación primaria y secundaria nos permitirá ampliar el panorama y el acercamiento a esta región tan lejana. Para ello se van a extraer las principales claves conceptuales y los factores que van a propiciar este desarrollo de la sociedad de la información en Corea del sur.

La evidencia empírica señala la existencia de un amplio grado de variabilidad entre las políticas que sobre la sociedad de la información se definen y se aplican en diferentes países, mostrando así mismo que la orientación de esas políticas ha experimentado variaciones significativas en el tiempo y en el espacio.

Palabras clave:

Política educativa coreana, tecnologías de la información y de la comunicación, Sociedad de la Información, sociedad de la información e innovación educativa.

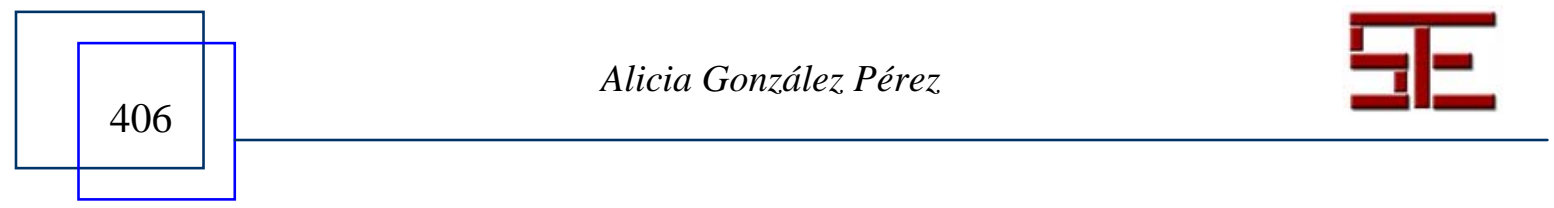




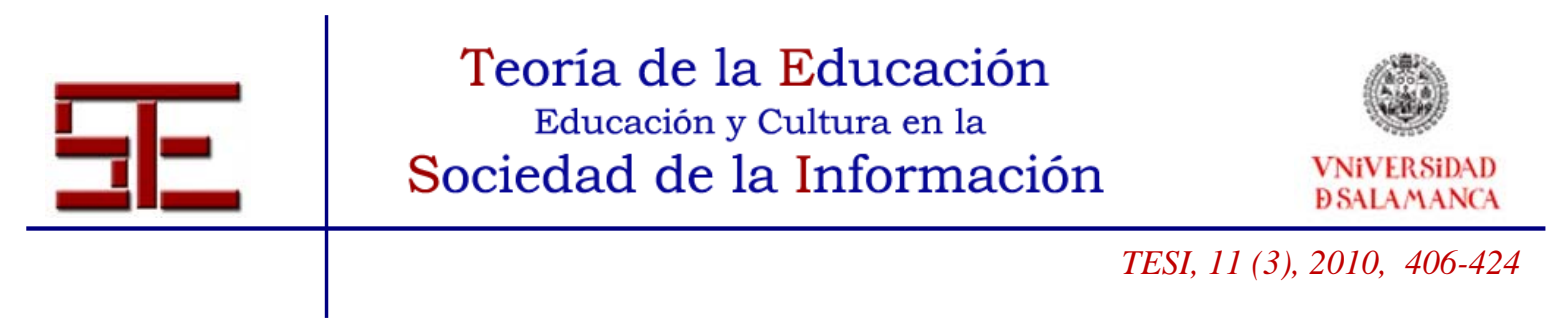

\title{
PUBLIC EDUCATIONAL POLITICS IN SOUTH KOREA IN THE FORMATION OF THE INFORMATION SOCIETY
}

\begin{abstract}
:
The target of this article is to study and to analyze the public educational politics of the Information Society in South Korea from the end of last century until nowadays. To see the translation of these politics in concrete performances inside the Korean educational system and especially in the primary and secondary education, will allow us to extend the panorama and the approach to this distant region. For this we are going to extract the main conceptual keys and the factors that are going to propitiate this development of the information society in South Korea. The empirical evidence indicates the existence of a wide grade of changeability between the politics that on Information Society are defined and are applied in different countries, showing likewise that the orientation of this politics have experienced changes on time and space.
\end{abstract}

Key words:

Korean political education, information and communication technologies, information society and educational innovation.

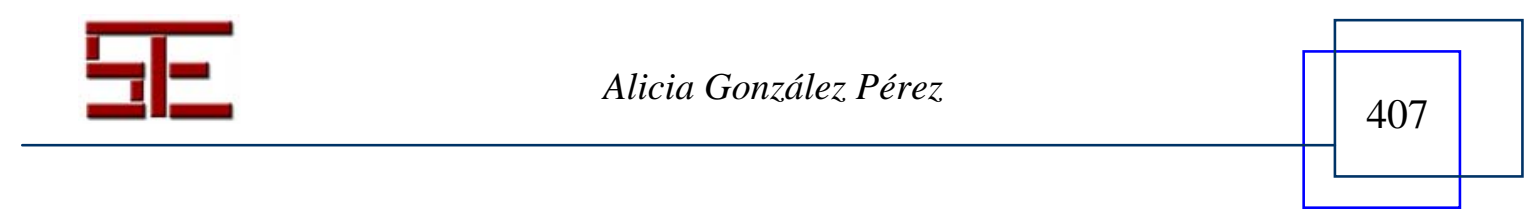




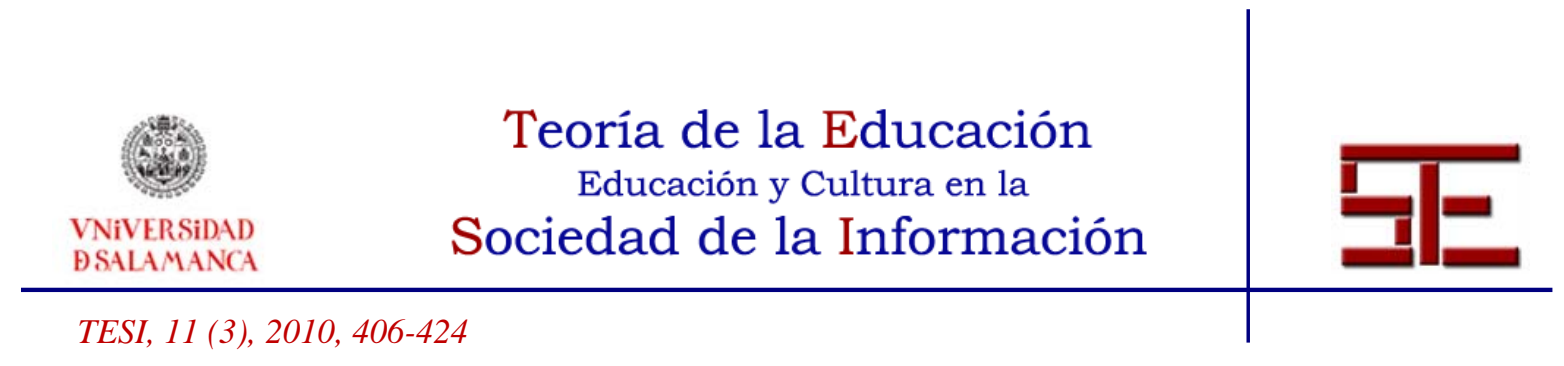

\title{
POLÍTICAS EDUCATIVAS PÚBLICAS EN COREA DEL SUR EN LA FORMACIÓN DE LA SOCIEDAD DE LA INFORMACIÓN
}

Fecha de recepción: 30/01/2009; fecha de aceptación: 03/06/2009; fecha de publicación: 28/02/10

\author{
Alicia González Pérez \\ aliciagp@us.es \\ Universidad de Sevilla
}

\section{PLANTEAMIENTO INICIAL}

Es importante diferenciar dos conceptos claves a los que se va a aludir a lo largo de este artículo. Uno es qué se entiende por sociedad de la información y el otro es qué aspectos recoge el concepto de sociedad del conocimiento.

La introducción al informe Bangemann se expresaba del siguiente modo:

"En todo el mundo, las tecnologías de la información y las comunicaciones están generando una nueva revolución industrial que ya puede considerarse tan importante y profunda como sus predecesoras. En una revolución basada en la información, la cual es en sí misma expresión de conocimiento humano (...) Esta revolución dota a la inteligencia humana de nuevas e ingentes capacidades y constituye un recurso que altera el modo en que trabajamos y convivimos".

Sin embargo, la UNESCO ha apoyado la expresión sociedad del conocimiento en el marco de sus políticas institucionales. Se trata de una concepción más integral, no relacionada únicamente con la dimensión económica. Abdul Waheed Khan, subdirector general de la UNESCO para la comunicación y la información, establece la siguiente diferenciación:

"La Sociedad de la Información es la piedra angular de las sociedades del conocimiento. El concepto de la sociedad de la información, a mi parecer, está relacionado con la idea de la innovación tecnológica, mientras que el concepto de sociedades del conocimiento incluye una dimensión de transformación social, cultural, económica, política e institucional, así como una perspectiva más

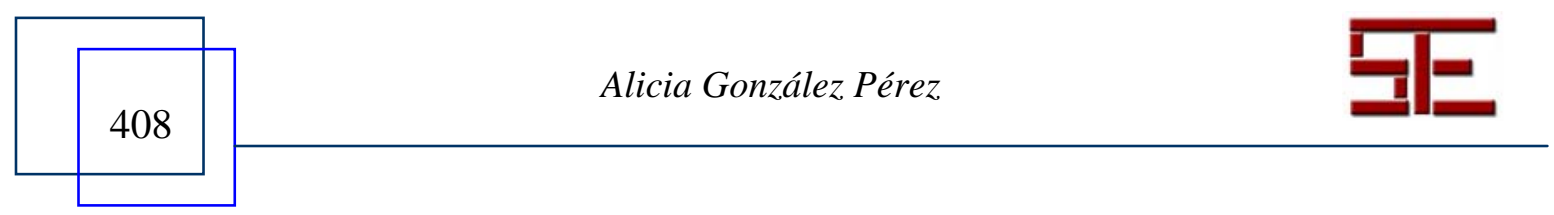




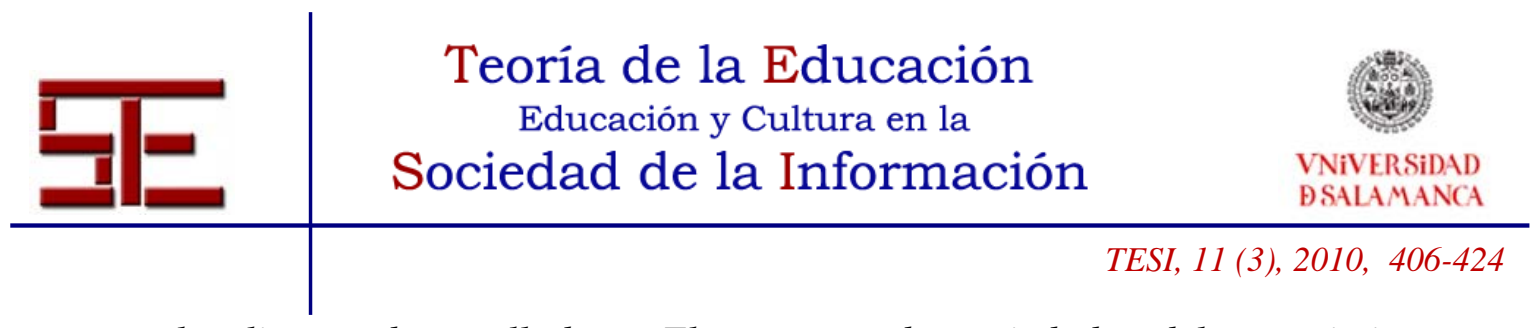

pluralista y desarrolladora. El concepto de sociedades del conocimiento es preferible al de la sociedad de la información ya que expresa mejor la complejidad y el dinamismo de los cambios que se están dando. (...) el conocimiento en cuestión no sólo es importante para el crecimiento económico sino también para empoderar y desarrollar todos los sectores de la sociedad”. (MEC, 2007, 27).

De esta definición se puede deducir que la UNESCO considera que más que estar en una sociedad de la información estamos en una sociedad del conocimiento. Con ello se quiere dar cuenta de la utilización de la información y la comunicación, de manera que pueden ser utilizadas en todas las áreas de actividad humana para mejorar las relaciones entre las personas y de estas con su entorno:

"Las sociedades del conocimiento deben estar basadas firmemente en la afirmación de los derechos humanos y de las libertades fundamentales, incluyendo la libertad de expresión. Dichas sociedades deberían asegurar la plena realización del derecho a la educación y a los derechos culturales. En las sociedades del conocimiento, el acceso al dominio público de la información y del conocimiento para propósitos educativos y culturales debería ser lo más amplio posible, asegurando la provisión de información de alta calidad y diversificada. Además, debiera enfatizarse la diversidad de lenguas y de culturas".

En 1994, en la conferencia de Buenos Aires de la Unión Internacional de Telecomunicaciones ${ }^{1}$, el vicepresidente estadounidense, Al Gore, introdujo el concepto de infraestructura global de la información. Dicho concepto dio paso a considerar la sociedad de la información como una nueva sociedad, en la que los servicios por medio de tecnologías de la información y la comunicación van a estar presentes en toda actividad humana.

Se precisa por ello particularizar la evolución de la sociedad de la información en el caso de Corea del sur y para ello se va a hacer un estudio pormenorizado de la realidad coreana teniendo en cuenta las diferentes etapas que van a conformar el mapa de las políticas educativas en lo que se refiere a la aplicación de las TIC en la educación. Se destacarán también los factores básicos que influyeron de forma determinante en el despegue de políticas públicas cuyo objetivo era generalizar las TIC a toda la población a través del fomento y aplicación de políticas educativas desde los primeros años escolares.

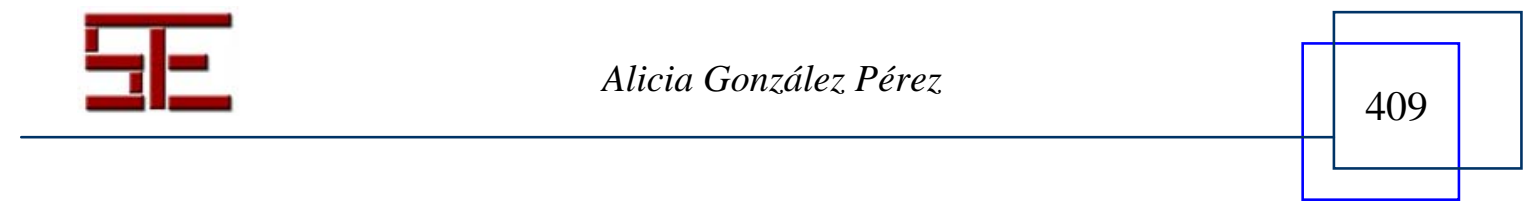




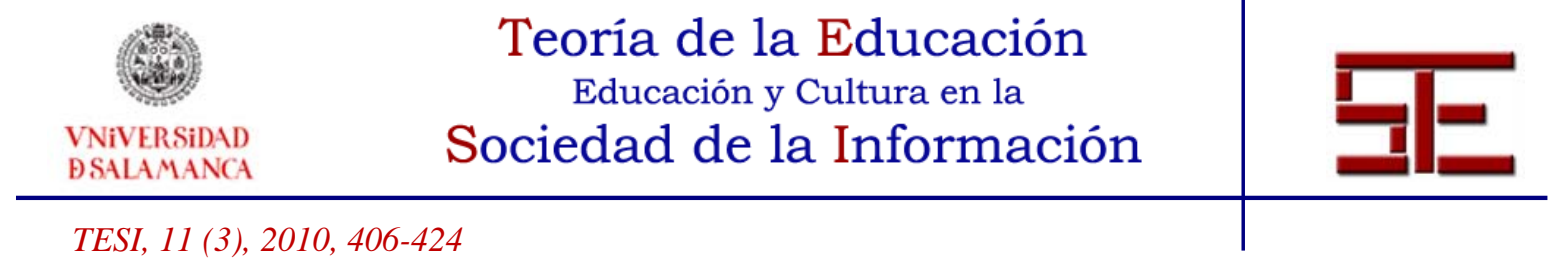

\section{MODELO GENERAL DE SOCIEDAD DE LA INFORMACIÓN}

Sociedad de la Información, según el último informe de la Fundación Telefónica de España, es un estadio de desarrollo social caracterizado por la capacidad de sus miembros (ciudadanos, empresas y Administraciones Públicas) para obtener y compartir cualquier información, instantáneamente, desde cualquier lugar y en la forma que se prefiera. Se trata de un nuevo tipo de sociedad donde la creación, modificación y distribución de la información forma parte esencial de su actividad económica y social. Este modelo no pretende plantear de una manera completa toda la complejidad del mundo real sino que se quiere que resulte una herramienta de utilidad para describir los principales componentes de la Sociedad de la Información de una manera concisa y clara.

La particularidad de este modelo es que puede ser un referente para otras sociedades, ya que en ellas también se podrían estructurar los componentes de la Sociedad de la Información, de esta manera, a pesar de que unos tengan más representatividad o ganen más importancia en unas sociedades y no en otras.

A continuación se presenta un esquema que de forma detallada acoge todos los elementos que componen dicho modelo de Sociedad de la Información. Éstos son cuatro: participantes, universo multimedia de servicios y contenidos, infraestructuras y entorno.

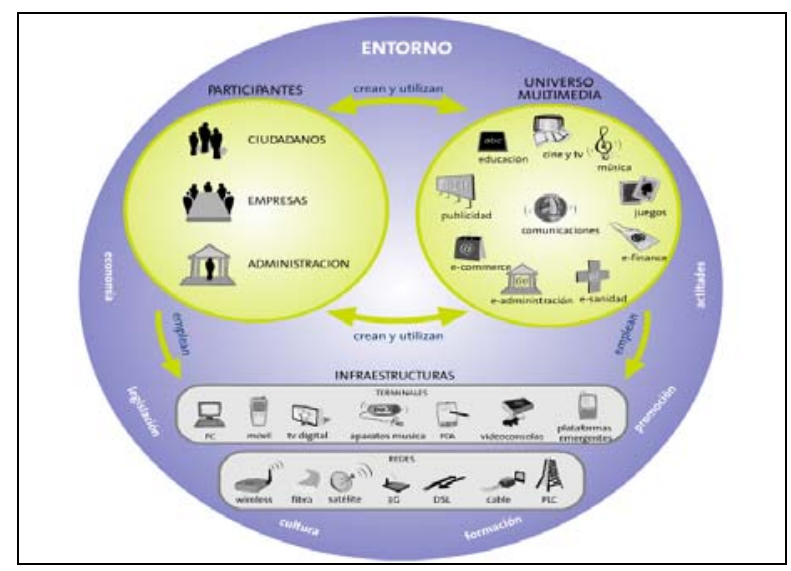

Gráfico 1. Modelo de Sociedad de la Información, 2007

Los participantes son los agentes (individuos u organizaciones) que crean y utilizan los contenidos y servicios que se proporcionan a través de las infraestructuras de

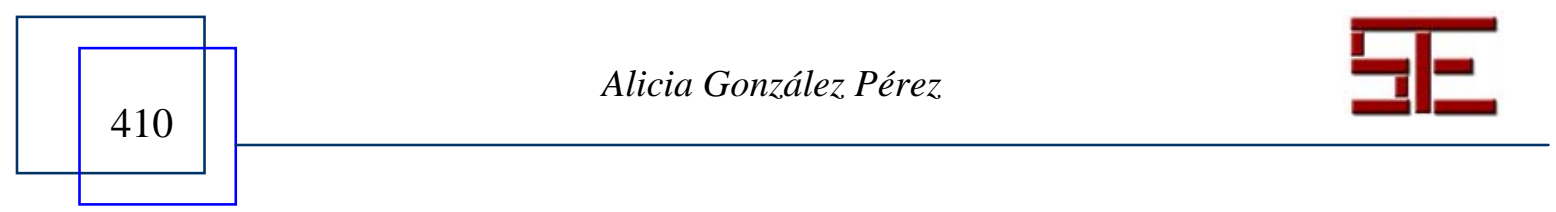




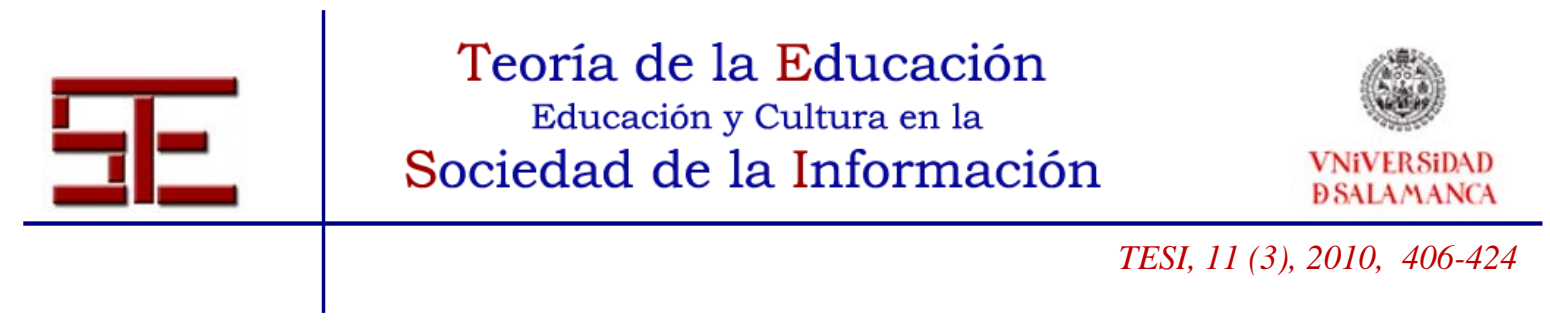

comunicación. Son, por tanto, el centro alrededor del cual gira el desarrollo de la propia Sociedad de la Información. Para una mejor comprensión se han considerado tres tipos de agentes en este grupo:

- Ciudadanos: que se trata de las personas en su faceta de vida no profesional, aunque sea un aspecto menos claro en el caso de profesionales independientes.

- Empresas: considerando como tales las organizaciones lucrativas, aunque se incluyan también en este grupo las organizaciones independientes sin ánimo de lucro, que en su organización y funcionamiento aplican procedimientos de gestión empresarial.

- Administraciones Públicas: en las que se incluyen las organizaciones que, a cualquier nivel, tienen como objetivo el servicio al ciudadano y la administración de los bienes públicos.

El universo multimedia de servicios y contenidos está formado por el conjunto de informaciones, bienes y servicios a los que se puede acceder desde las infraestructuras de telecomunicación disponibles. Entre los productos a los que se puede llegar, por ejemplo, a través de Internet, algunos son convertibles en bits. En este caso es posible llevar a cabo una transacción comercial completa (solicitar el producto, recibirlo y pagarlo) a través de este medio. En otras ocasiones, cuando los objetos son físicos, sólo podrán realizarse algunas operaciones a través de la red (solicitar el producto y pagarlo). $\mathrm{Y}$ en otras, lo único que se requerirá es acceso a información o a un determinado servicio. En todas esas acciones el usuario está accediendo a contenidos. Se pueden destacar cuatro áreas:

- Comunicación: se trata del conjunto de servicios que facilitan la comunicación entre los usuarios y comprenden desde las aplicaciones de telecomunicación tradicionales (telefonía fija y móvil) a los servicios de comunicación más relacionados con Internet y las nuevas tecnologías (correo electrónico, Chat, mensajería instantánea, SMS, etc.).

- Búsqueda y descarga de información: consiste en el acceso a un servidor en el cual el usuario selecciona y recupera la información que le interesa. Esta información puede estar disponible gratuitamente o ser necesario un pago. Dentro de este grupo se pueden encontrar los portales y buscadores (que acercan la información que le interesa al usuario) y, en general, los sitios con información.

- Comercio electrónico: se trata del conjunto de servicios en los que el usuario selecciona y/o realiza algún tipo de pedido de un bien físico o digital.

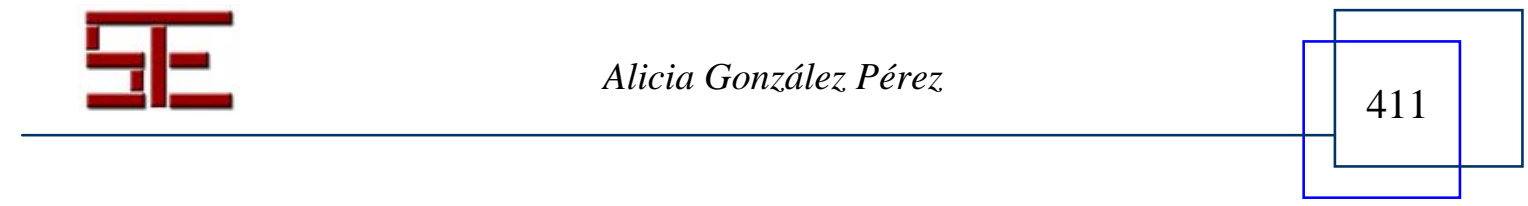




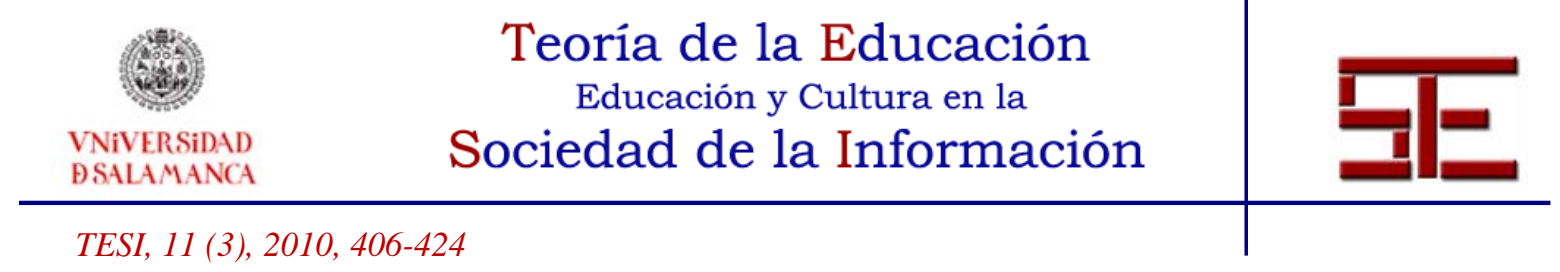

- $\quad$ Servicios en red (en este caso la palabra servicio se emplea en el sentido del sector terciario). Estos servicios permiten que el usuario ejecute, a través de la red, un proceso cuyo resultado sea enviado, normalmente, como información (por ejemplo, servicios financieros, reservas de hotel, compra de billetes de medios de transporte, servicios de la Administración Pública como sanidad, educación, participación ciudadana, hacienda, etc.).

Las infraestructuras, sin embargo, son el conjunto de medios técnicos, físicos y lógicos que permiten a los usuarios acceder a la oferta de contenidos. Las infraestructuras son el nexo de unión entre la oferta de contenidos y la demanda de los usuarios y están constituidas por tres pilares fundamentales:

- Terminales: se trata de los dispositivos que se encuentran en el extremo “usuarios” de la cadena de comunicación y constituyen el punto donde se produce el contacto entre el usuario y los contenidos.

- Redes: son los equipos y sistemas que establecen la conexión entre los terminales y los servidores o entre dos terminales (cuando es el usuario el que actúa como servidor). La utilización de las infraestructuras físicas que constituyen las redes se comercializa en forma de servicios de comunicaciones y éstos a su vez posibilitan el acceso a contenidos y servicios proporcionados por terceros.

Finalmente, quedaría destacar el entorno donde se encuentran todos los elementos a los que se ha hecho referencia anteriormente. En el entorno los elementos básicos de la Sociedad de la Información se desenvuelven en un medio económico y social del que no son independientes. Por lo tanto, se incluyen dentro del concepto de entorno aquellos factores que tienen una influencia decisiva en el desarrollo de la Sociedad de la Información, pero que existen con independencia de ésta, como, por ejemplo, economía, legislación, cultura, formación, etc.

\section{INFLUENCIA DE LA SOCIEDAD DE LA INFORMACIÓN EN LA POLÍTICA EDUCATIVA COREANA}

"La política educativa trata, esencialmente, de las directrices que señalan los Gobiernos para organizar la educación del país, en el marco de su política general y nacionalista, de acuerdo con el programa electoral del partido y en cumplimiento de los principios de la Constitución (Carta Magna o Leyes Fundamentales del Estado). Los criterios y la orientación deben inspirar: los fines, la estructura, la organización, la administración, los contenidos, los

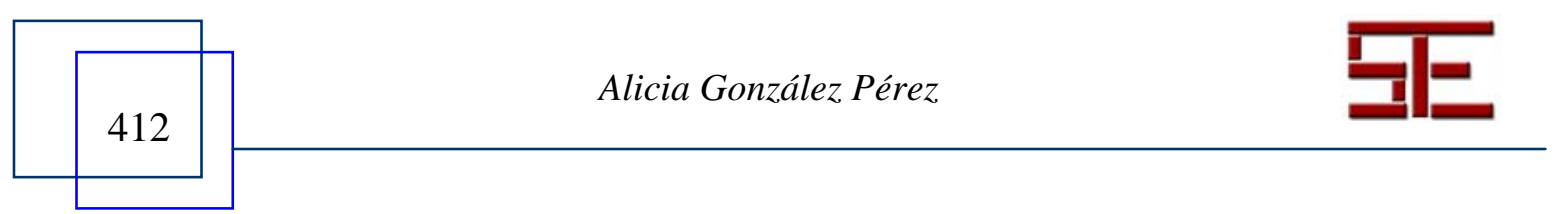




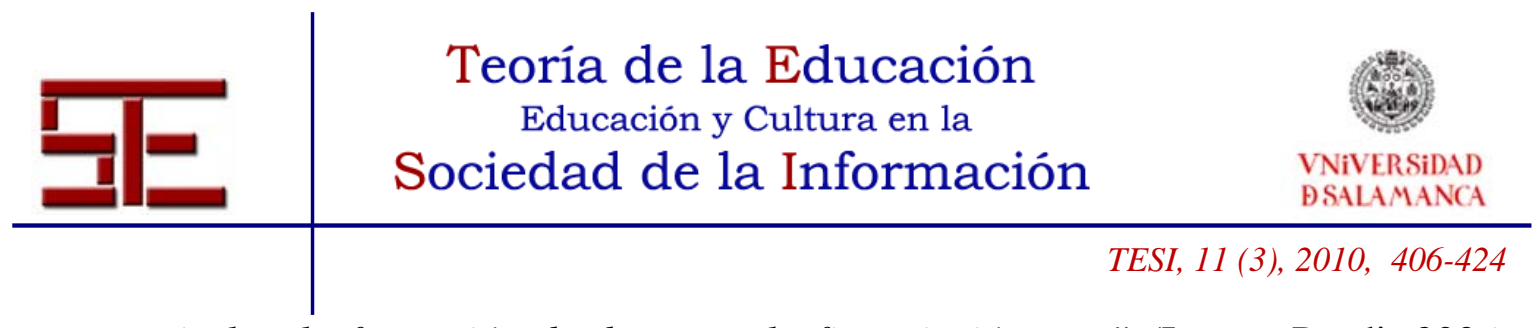

niveles, la formación de docentes, la financiación, etc.” (Iyanga Pendi, 2006, 112).

Sin embargo, la política educativa ha estado fuertemente influenciada en cada sociedad por las grandes corrientes de pensamiento, así como por las necesidades y aspiraciones propias de cada época. Las reformas de la educación no se plantean sólo como instrumento de gestión, sino como política de expansión y mejora e innovación en la educación.

La política educativa no puede ser improvisada, sino que debe fundarse en dos consideraciones: en la realidad del país y en las necesidades de los ciudadanos, por consiguiente, ha de basarse en el conocimiento y apreciación de los siguientes sectores: la población, con sus características humanas, la tradición histórica y el nivel cultural; el sistema económico, con sus recursos, la renta nacional, los servicios disponibles o requeridos y el nivel profesional existente y demandado; el sistema político, que refleja la posibilidad u oportunidad de reformas, y las ideologías existentes; el sistema educativo, con las instituciones y procedimientos existentes, el personal disponible, las tasas de escolarización, los éxitos y abandonos, los costos de la educación y los estudios comparativos. Para este trabajo se ha de contar con un equipo de pedagogos, sociólogos, psicólogos, economistas y expertos en otras ramas. Ésta es una de las razones por las que se ha intentado dar una visión global a lo largo de todo este trabajo acerca de cómo ha ido evolucionando la sociedad coreana en los distintos niveles mencionados anteriormente.

El análisis de los textos políticos aporta un compendio de indicadores que contribuyen a la delimitación de la noción de innovación educativa en base a tres vertientes: social, institucional y curricular. Las dimensiones halladas configuran el enfoque político sobre qué se entiende por buenas prácticas basadas en TIC, qué aspectos les dan entidad o valor y qué criterios se utilizan para promoverlas, seleccionarlas e incentivarlas. Estos indicadores constituyen una herramienta de gran utilidad para orientar los contenidos curriculares y las competencias profesionales a desarrollar en la formación inicial de los docentes (De Pablos Pons y Jiménez Cortés, 2007, 24).

Existe un consenso bastante generalizado sobre la necesidad de que las administraciones públicas intervengan activamente en promover el tránsito hacia la Sociedad de la Información, así como en atribuir a Corea, Estados Unidos, Singapur, Finlandia o Suecia, como referentes positivos de la puesta en práctica de políticas públicas adecuadas que fomenten el uso de las TIC en su población. Sin embargo, del mismo modo que los modelos de la sociedad de la información emergentes en esos países son

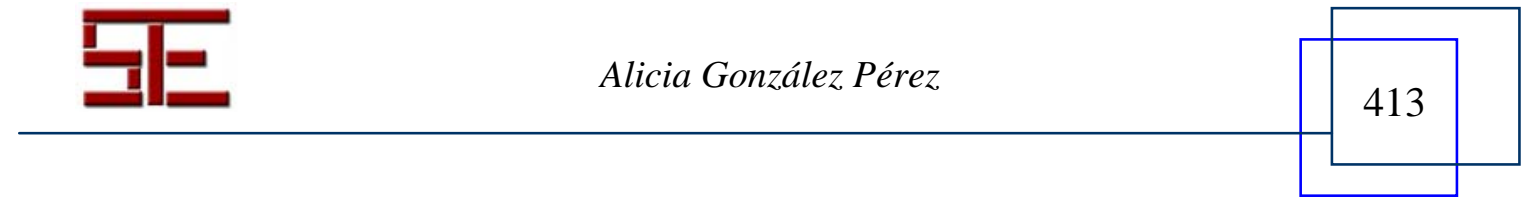




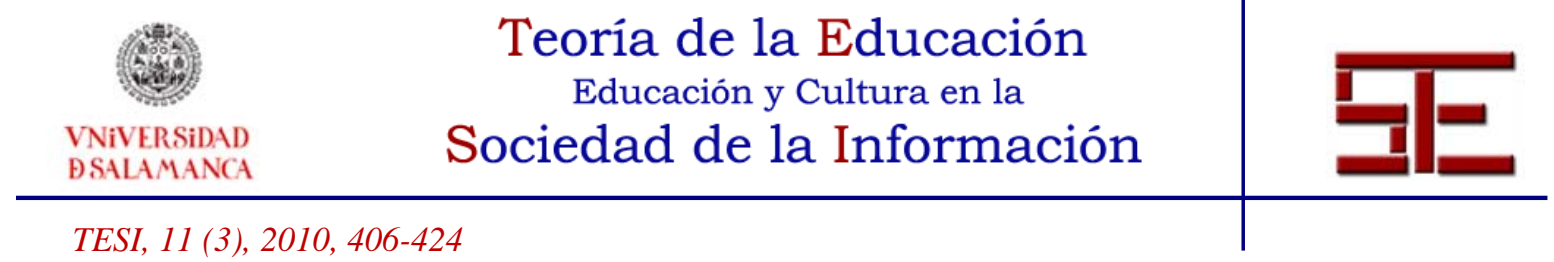

distintos, también lo son las políticas públicas puestas en práctica por las respectivas administraciones. Dado que la actuación de las administraciones no se produce en el vacío, una parte del éxito de esas políticas puede atribuirse no sólo a su buena adaptación a los requisitos de las tecnologías, sino también a su adecuación a las condiciones particulares del entorno social y económico en el que se diseñaron y pusieron en práctica.

En Corea, el Ministerio de Educación, Ciencia y Tecnología ${ }^{2}$ (MEST) es la máxima institución educativa que se encarga de desarrollar las coordenadas y directrices de las políticas educativas del país, estableciendo un marco estratégico para la búsqueda de calidad y eficacia, desde la igualdad de condiciones para el acceso a las TIC, ante los nuevos desafíos de la globalización. Un punto fuerte de la política educativa coreana ha sido la apuesta por la introducción de las TIC en la educación. Por ello, el e-learning está siendo impulsado en todos los niveles educativos como estrategia nacional para integrar a la población en la sociedad del conocimiento y construir una comunidad educativa de aprendizaje online.

\section{1.- Condicionantes de la política educativa en Corea del Sur}

En el artículo 31 de la Constitución Nacional de Corea (1948) se recoge el derecho de una educación igualitaria para todos, respetando las condiciones particulares de cada uno. Por ello, el Estado ha de proporcionar una educación de calidad a lo largo de toda la vida que se adapte a los cambios sociales, políticos, económicos, educativos y culturales que se producen. Actualmente se apuesta por un modelo educativo adaptado a una sociedad cambiante donde las TIC son entendidas, no sólo como el aprovechamiento funcional de éstas para fines formativos, sino también como un elemento de transformación social, cultural, económica, política e institucional. Pero todo esto debe estar sostenido en la afirmación de los derechos humanos y de las libertades fundamentales.

También se hace imprescindible resaltar el artículo 23 de la Ley de Educación Coreana, el cual está basado en el artículo 31 de la Constitución Nacional. En este artículo se contempla que el gobierno y los auto gobiernos de las provincias han de establecer e implementar las políticas educativas necesarias para la integración de las TIC en los procesos de enseñanza-aprendizaje. En el apartado segundo de dicho artículo se hace explícito que "el gobierno y los auto gobiernos de las provincias han de establecer políticas de gestión educativas en la administración y en los centros, que permitan el procesamiento electrónico de las tareas”. Actualmente, el papel que han pasado a tener

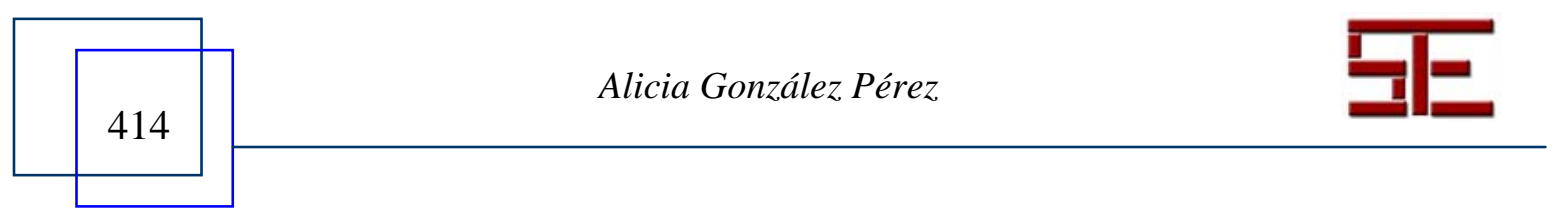




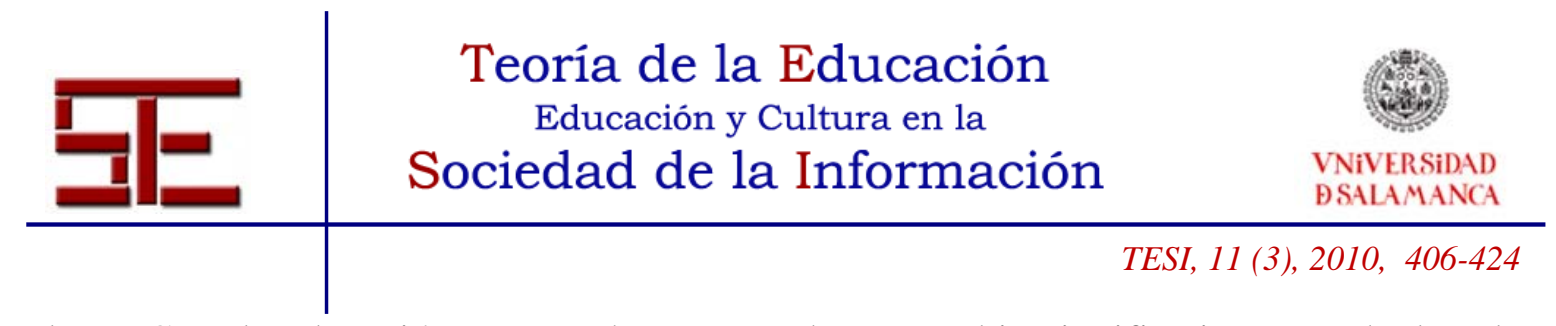

las TIC en la educación coreana ha provocado un cambio significativo y gradual en la práctica educativa de toda la comunidad educativa coreana.

Después de la reforma educativa que tuvo lugar el 31 de mayo de 1995, se comienza a gestar el $7^{\circ}$ currículo nacional cuyo objetivo principal fue impulsar un nuevo currículo nacional en todas las escuelas públicas y nuevos métodos de enseñanza, los cuales habían de atender a una educación abierta, especialmente en los primeros años de la escuela. La nueva jerga educativa traía consigo el uso de una serie de palabras que configuraban un léxico peculiar: necesidades, diversidad, especialidad, elección, entre otras. Algunas frases que acompañan el concepto de educación abierta incluían cosas como "el profesor como asistente", "el valor de las habilidades no académicas igual que las académicas", "los procesos de enseñanza-aprendizaje son tan importantes como los resultados obtenidos en los test” (Jeong Won Kim, 2004, 128).

Es en esta reforma cuando el gobierno trata de fomentar el cambio en las escuelas públicas con el fin de atender las nuevas necesidades que la sociedad de la información trae consigo. A partir de este momento las TIC comienzan a ganar importancia y se llevan a cabo importantes inversiones para dotar de infraestructuras a los centros educativos. Por ello, se concretan cuatro iniciativas, que tienen por objeto crear una serie de necesidades en la población coreana. Éstas son la creación de una base legislativa sobre las TIC, la dotación de equipamiento y conexión a Internet de los centros y el fomento de las TIC en todas las esferas de la vida cotidiana.

\begin{tabular}{|c|c|c|}
\hline $\begin{array}{l}\text { Etapa Inicial } \\
1996-2000\end{array}$ & $\begin{array}{c}\text { Etapa Uso TIC } \\
\text { 2001-2005 }\end{array}$ & $\begin{array}{l}\text { Etapa } \\
\text { e-learning } \\
2006 \sim\end{array}$ \\
\hline $\begin{array}{l}\text { •Reforma } \\
\text { Educativa }\end{array}$ & $\begin{array}{l}\text {-Recursos Educativos: } \\
\text { EDUNET }\end{array}$ & \multirow{4}{*}{$\begin{array}{l}\text {-Desarrollo de } \\
\text { contenidos } \\
\text { educativos de } \\
\text { Calidad } \\
\text {-Formación del } \\
\text { profesorado en } \\
\text { prácticas escolares } \\
\text { con TIC } \\
\text {-Análisis de la } \\
\text { introducción de las } \\
\text { TIC en la escuela }\end{array}$} \\
\hline $\begin{array}{l}\text { - Infraestructuras } \\
\text { TIC en todas las } \\
\text { escuelas }\end{array}$ & $\begin{array}{l}\text { - Mejora de los equipos } \\
\text { informáticos }\end{array}$ & \\
\hline $\begin{array}{l}\text { •Formación en } \\
\text { TIC a } \\
\text { determinados }\end{array}$ & $\begin{array}{l}\text { - Mantenimiento de la } \\
\text { infraestructura } \\
\text { tecnológica }\end{array}$ & \\
\hline $\begin{array}{l}\text { colectivos } \\
\text { sociales }\end{array}$ & $\begin{array}{l}\text {-Formación del } \\
\text { Profesorado en el uso } \\
\text { de las TIC }\end{array}$ & \\
\hline Master Plan I & Master Plan II & Master Plan III \\
\hline
\end{tabular}

Gráfico 2. Evolución de la incorporación de las TIC en la educación

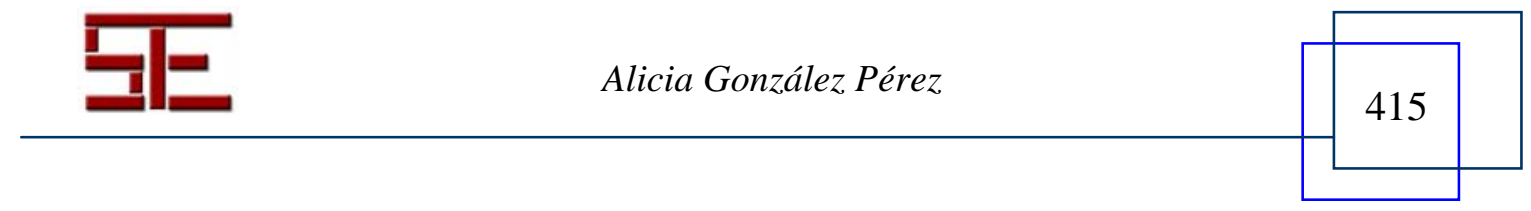




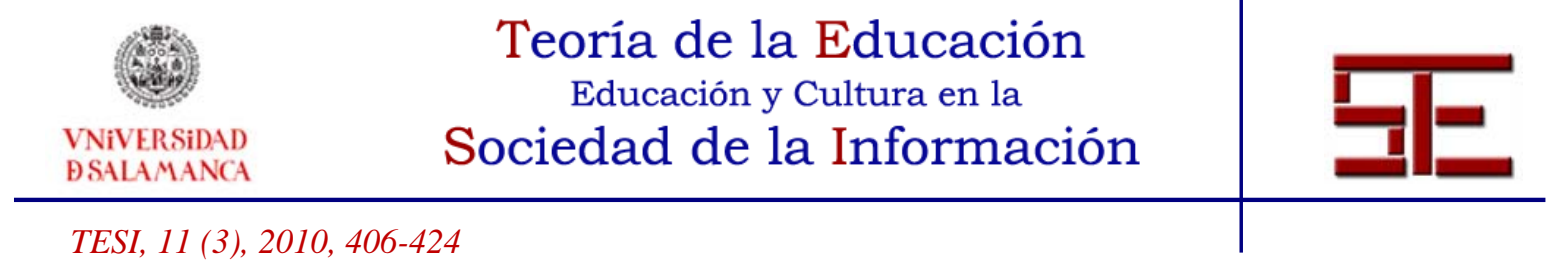

Como se ha dicho anteriormente, es en los años 90 cuando se comienza a dibujar un marco legislativo base con la Ley para la Promoción de las TIC. Éste se concreta en julio de 1996 en el I Plan de Adaptación de la Educación a la Sociedad de la Información. Este plan se concreta en una reforma del sistema educativo que pretende estimular el desarrollo de los procesos y habilidades mentales, donde destacan, como objetivos de primer orden, el pensamiento analítico, el pensamiento pragmático y el pensamiento dialéctico (crítico y creativo). Este modelo pedagógico trata de fomentar una enseñanza más interdisciplinar y centrada en el alumno, donde lo más importante es su proceso de aprendizaje con la ayuda, orientación y mediación del profesor. En definitiva, se trata de que adquieran una serie de competencias que las reformas anteriores no habían considerado.

A consecuencia de la implantación del I Plan de Adaptación de la Educación a las TIC, en 1997 se empieza a dotar de infraestructuras que proporcionen servicios de Internet a todos los centros de educación primaria y secundaria. En el 2000, Kim Jun Jyung (Director de la Oficina de Información y Comunicación Tecnológica del MOE\&HRD) decía:

"Nosotros planeamos tener un laboratorio informático en este año. Todas las clases estarán equipadas con ordenadores y acceso a Internet. Cada profesor tendrá un ordenador en su clase” (Kim Jun Jyung, 2000) ${ }^{3}$.

En julio de 2000, el MOE\&HRD (Ministerio de Educación), el MIC (Ministerio de Información y Comunicación) y "Korea Telecom” firmaron un acuerdo que pretendió dotar de un servicio gratuito y descuentos especiales durante cinco años para la educación primaria y secundaria con el fin de mejorar los servicios de Internet en las aulas y establecer una red de alta velocidad. El objetivo de esta iniciativa no era otro que el desarrollo de redes, servicios y terminales de banda ancha en todas las escuelas para extender el valor de su uso a todos los coreanos.

Consecuencia del plan anterior, en mayo de 2001 el gobierno coreano anunciaba el II Plan de Adaptación de la Educación a las TIC que se desarrolló entre 2001 y 2005. En este II Plan el MOE\&HRD priorizaba una serie de líneas de actuación que daban importancia al tema de recursos educativos, de mejora de los equipos informáticos, mantenimiento de toda la infraestructura tecnológica tanto en las escuelas como en las oficinas de educación. Pero detrás de toda esta infraestructura física se estaba creando un sistema que permitiría compartir recursos educativos y apoyaría el desarrollo y mejora de contenidos educativos: EDUNET.

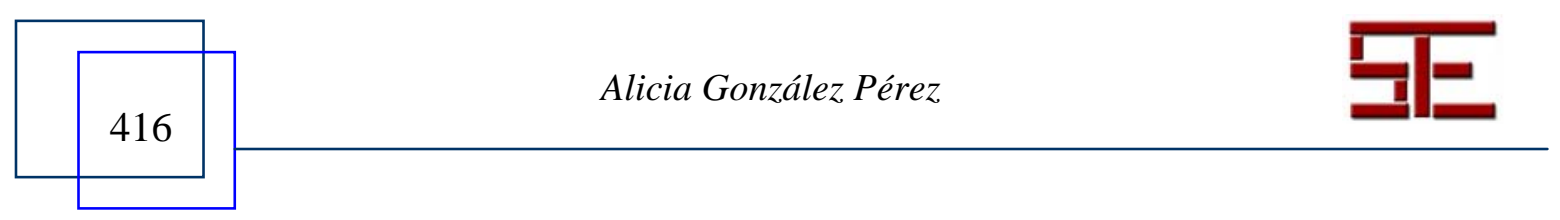




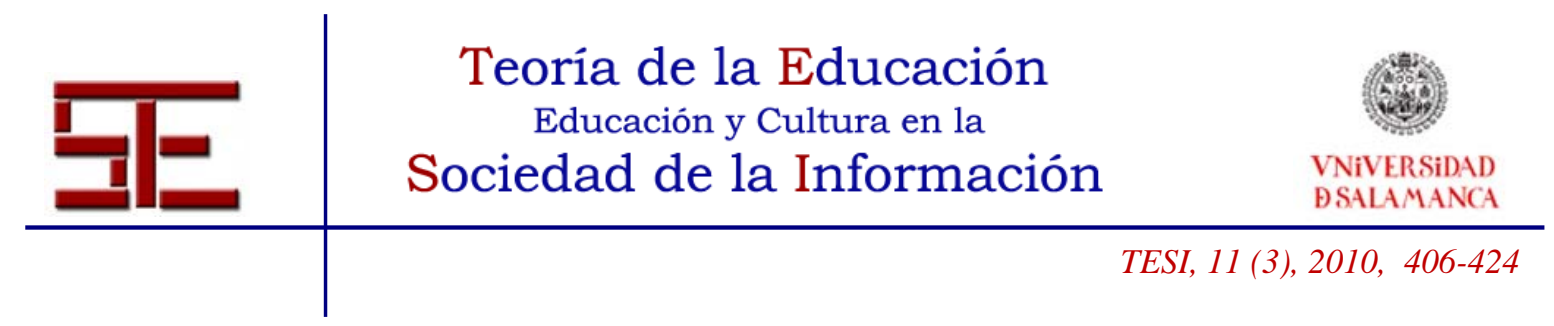

EDUNET es un servicio educativo que permite que tanto profesores, alumnos y público en general tengan acceso a información educativa de interés y además puedan crear comunidades de aprendizaje. Junto a esto propone una metodología de trabajo grupal que favorezca el intercambio de información.

En 2001, el gobierno subvencionó el coste del equipamiento completo de Internet a las escuelas nacionales de primaria y secundaria y el 50\% a las escuelas de primaria y secundaria afiliadas a las oficinas de educación. En 2002, la cantidad de fondos que el gobierno invirtió en las 28 escuelas nacionales fue de 160 millones de wones mientras que en las 9.194 escuelas públicas y privadas se invirtieron unos 8,47 billones de wones. En 2003, se invirtieron 113 millones de wones en las escuelas nacionales y 5,347 billones de wones en las 9.641 escuelas públicas y privadas. Finalmente, en 2004 alrededor del $13 \%$ del coste total del equipamiento de Internet en las escuelas nacionales fue financiado por el gobierno con un total 112 millones de wones mientras que 6,635 billones wones fueron repartidos a las 9.521 escuelas públicas y privadas (Libro blanco MOE\&HRD y KERIS, 2005, 39).

Según datos oficiales del Ministerio de Educación Coreano, en diciembre de 2004 había una media de un 1 ordenador por cada 6,1 estudiantes. A partir de estos datos, el compromiso para 2005 era conseguir que hubiera 1 ordenador para cada 5 estudiantes. No obstante, es necesario contemplar las diferencias entre las escuelas, ya que en algunas escuelas primarias había un ordenador por cada 6,1 alumnos, en escuelas de secundarias obligatoria había 1 PC por cada 4,2 estudiantes y en algunas escuelas especiales había 1 PC por cada 1,9 estudiantes. Viendo la necesidad de que las escuelas primarias son las que tienen una ratio menor en cuanto a ordenadores por alumno se proponen medidas que van a priorizar la distribución de ordenadores en este nivel (Libro blanco MOE\&HRD y KERIS, 2005, 38).

A modo de conclusión se puede decir que las políticas educativas llevadas a cabo por el gobierno coreano hasta el momento trataron, no sólo, de crear una infraestructura de banda ancha para su uso en la escuela, sino también, la implementación de TIC en el proyecto educativo de centro. En 2004, la responsabilidad para adaptar los proyectos educativos de centro a las TIC fue transferida a las oficinas de educación y el papel que la escuela debía jugar en la nueva Sociedad de la Información también se adaptó a las directrices que marcaban organizaciones internacionales como la OCDE.

En 2006, el MOCIE (Ministry of Commerce, Industry and Energy) hacia público un paquete de medidas que aseguraban la calidad del sector educativo público hasta 2011. Destacaba seis áreas de actuación: mejorar las competencias TIC de profesores y

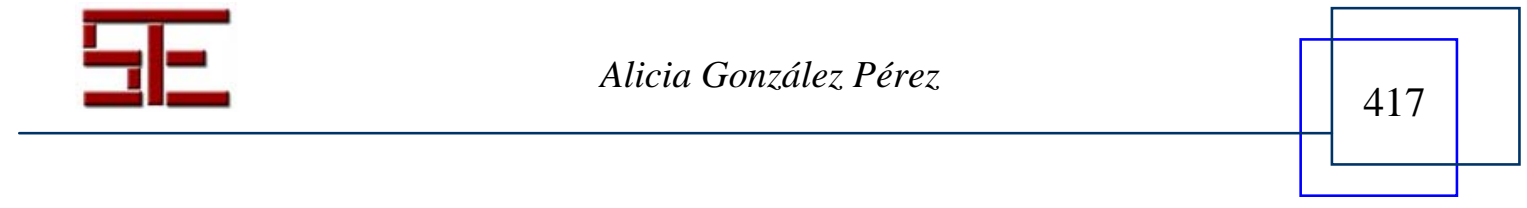




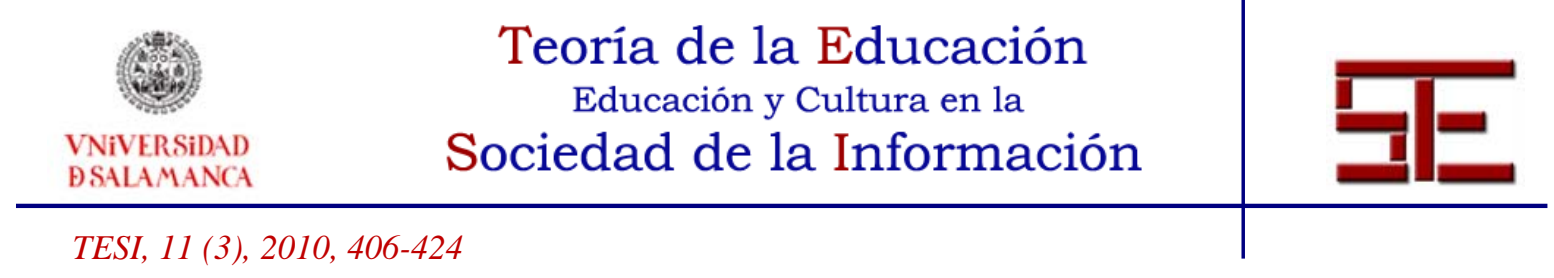

administradores, mejorar la calidad de los contenidos TIC y desarrollar sistemas de apoyo online basados en la colaboración.

Finalmente, añadir que según el informe de MOE\&HRD (2007) los objetivos que trabajan el tema de las TIC en educación primaria y secundaria están clasificados en cuatro categorías. Éstas son:

- Desarrollar contenidos de calidad que promocionen las TIC en los procesos de enseñanza-aprendizaje y ayuden a mejorar la educación pública.

- Descubrir e implantar programas de formación para profesores en prácticas escolares.

- Mejorar las infraestructuras TIC, así como el NEIS ${ }^{4}$, para subsanar las necesidades de una sociedad basada en el conocimiento.

- Poner en marcha proyectos que nos ayuden a analizar las consecuencias de la introducción de las TIC en el sistema educativo coreano.

\section{4.- MODELO ANALÍTICO DE LA SOCIEDAD DE LA INFORMACION EN COREA}

Como se ha dicho anteriormente cada país va a desarrollar un modelo de Sociedad de la Información diferente en el que se va a tener muy presente la realidad del país y las necesidades de los ciudadanos. Por consiguiente, este modelo ha de basarse en el conocimiento y apreciación de la idiosincrasia de la población, del sistema económico, del sistema político y del sistema educativo del momento.

A comienzos de la década de los 90, Corea no estaba situada entre la primera generación de países líderes en Internet. Sin embargo, la inestabilidad económica creada por la crisis de 1997 hace que el gobierno fomente una serie de estrategias que van a impulsar el uso de las TIC. Es decir, que Corea aprovechó un momento de inestabilidad económica para impulsar la industria de las telecomunicaciones y relanzar la economía del país. Para ello se apoyó en el potencial de su mercado interno comercializando y desarrollando la banda ancha. Su estrategia consistió en aprovechar el potencial de empresas consolidadas como "Korean Telecom", como operador de red, y de los fabricantes de electrónica de consumo, como Samsung, para la producción de terminales.

A partir de 1998, el gobierno fomentó la creación de negocios en red o relacionados con Internet ofreciendo beneficios y bajos préstamos. Estas políticas favorecieron el crecimiento de nuevas empresas dedicadas a Internet que coincidieron justamente con el auge y el uso de la web.

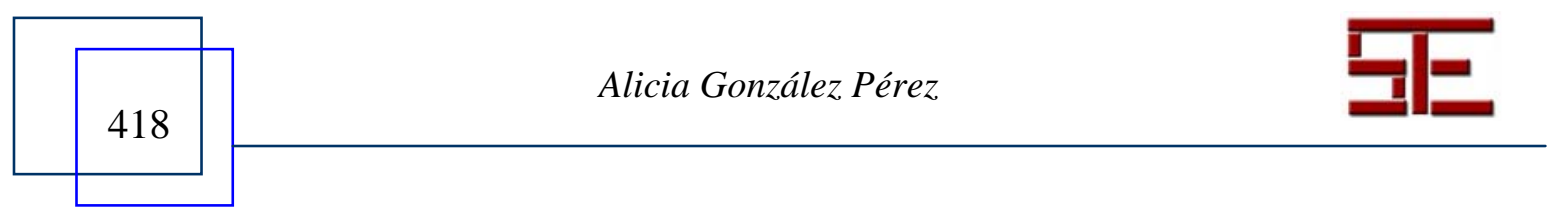




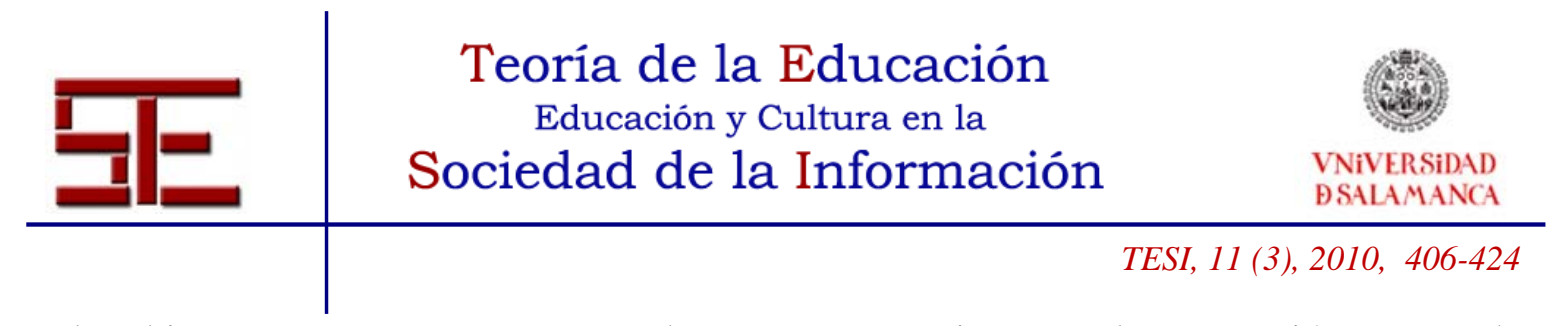

El gobierno coreano puso en marcha otras estrategias para la promoción y uso de Internet entre la población dirigidas especialmente a sectores sociales en exclusión, como granjeros, familias con bajos ingresos, mayores, prisioneros, personal militar, personal desempleado y discapacitados. Sin duda fueron las amas de casa el punto de mira más importante ya que ellas eran un eslabón clave para impulsar el cambio. En la sociedad coreana las mujeres son las que tienen el poder adquisitivo de sus hogares y por ello se hacia imprescindible convencerles de la importancia de Internet en los estudios de sus hijos, pues, de lo contrario, se podría ignorar la importancia de Internet. Ésta fue la principal razón por la que se tomó muy en serio estimular y trabajar con las amas de casa para que entre ellas hablaran sobre los efectos positivos que Internet podría tener para los estudios de sus hijos.

En 1999, muchas academias fueron subvencionadas para que impartieran cursos TIC destinados a las amas de casa. Gracias a estas subvenciones éstas podían hacer cursos sobre TIC a bajo precio. Estos programas tuvieron muchísimo éxito, lo que dio lugar a la aparición de numerosos portales en Internet destinados a este sector, en algunos de los cuales había más de un millón de mujeres suscritas. Fruto de este éxito el MIC incrementó el número de institutos de formación de 769 a 1057 en el $2003^{5}$.

En la siguiente tabla se concretan los referentes más importantes que en Corea impulsan la Sociedad de la Información.

\begin{tabular}{|c|c|}
\hline \multicolumn{2}{|c|}{ Referente Coreano de Sociedad Información (2000) } \\
\hline Referentes tecnológicos & $\begin{array}{l}\text { - Comunicaciones fijas de banda ancha: accesos } \\
\text { ADSL y de fibra óptica. } \\
\text { - Telefonía digital con contenidos multimedia }\end{array}$ \\
\hline Prácticas informacionales & $\begin{array}{l}\text { - Incentivo a la competencia entre operadores de } \\
\text { red privados. } \\
\text { - } \quad \text { Sdministración y Educación on-line } \\
\text { - Juegos Masivos sobre redes de banda ancha } \\
\text { - Video (y telenovelas) bajo demanda } \\
\text { - Innovación en terminales y electrónica }\end{array}$ \\
\hline Proyecto & $\begin{array}{l}\text { El desarrollo de redes, servicios y terminales de } \\
\text { banda ancha como impulso al crecimiento } \\
\text { económico. } \\
\text { Revitalizar la economía del país, incluyendo el } \\
\text { sector electrónico tras la crisis financiera de } \\
\text { 1997-98. } \\
\text { Ampliar el mercado para la industria electrónica } \\
\text { nacional }\end{array}$ \\
\hline Lenguaje y metáforas & $\begin{array}{l}\text { - El liderazgo tecnológico como palanca tanto para } \\
\text { el desarrollo interno como para el progreso } \\
\text { económico del país en la red mundial. Fuerte } \\
\text { liderazgo y refuerzo desde el Estado. }\end{array}$ \\
\hline
\end{tabular}

Gráfico 3. Referente Coreano de la Sociedad de la Información, $2000^{6}$

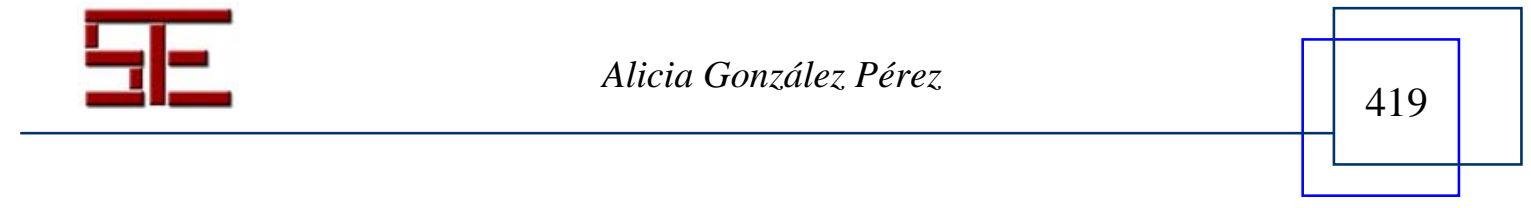




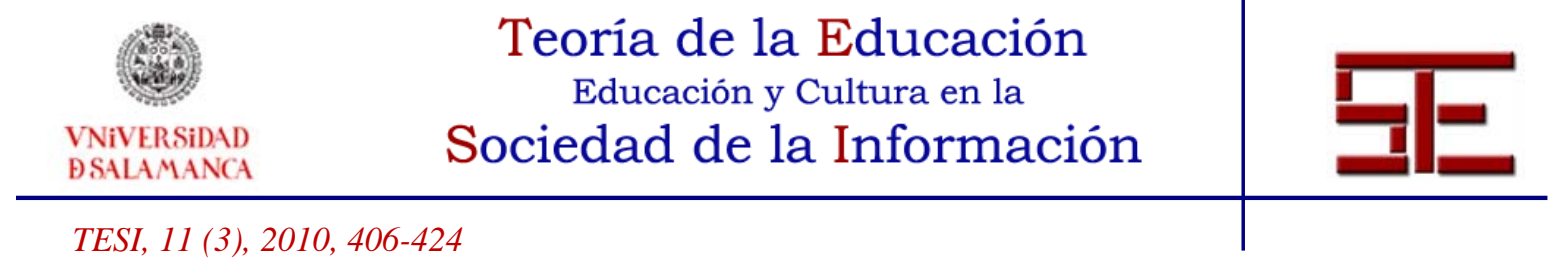

En este modelo se puede ver como en el concepto de Sociedad de la Información de Corea existen varias partes heterogéneas que se utilizan para construir las instancias particulares de la Sociedad de la Información. Éstas son:

- Potenciar las infraestructuras proporcionando banda ancha a todas las instancias de la población y dar a conocer nuevos dispositivos de última generación que permitan el uso de Internet móvil.

- La inserción del proyecto de Sociedad de la Información en un proyecto para el país.

- El uso de un lenguaje, muchas veces con rasgos metafóricos, para atraer adeptos a ese proyecto.

- El impulso a prácticas informacionales de transformación de las economías y/o la sociedad locales, utilizando las tecnologías al servicio del proyecto definido.

- Como se puede observar el concepto de Sociedad de la Información en Corea no tiene que ver tanto con las tecnologías sino con las condiciones institucionales, sociales y económicas del entorno. De hecho, el modo en que se concreta tal visión y se incorpora de un modo u otro al proceso de formación de las políticas es uno de los ingredientes cruciales del modelo que se pretende construir.

- El objetivo que se plantea es construir un modelo que ayude a hacer explícito cómo las administraciones públicas competentes traducen en estrategias las políticas que van a conformar el modelo de Sociedad de la Información en materia educativa, que el gobierno coreano hace explícitas para su país.

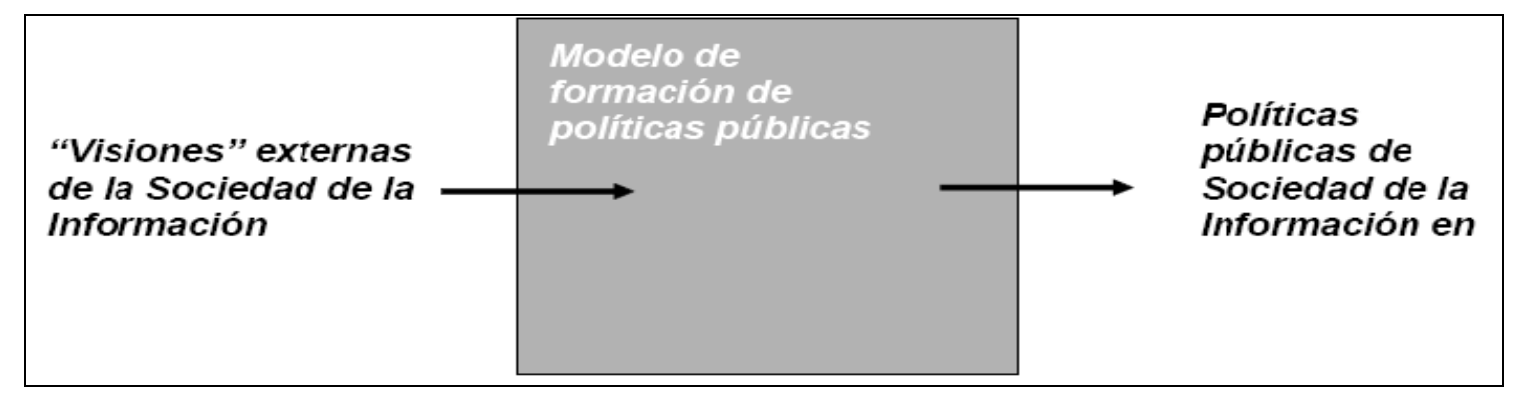

Gráfico 4. Modelo analítico de la Sociedad de la Información en Corea ${ }^{7}$

En resumen, el concepto de Sociedad de la Información está compuesto por un conjunto heterogéneo de elementos que están de un modo u otro presentes en todas las instancias del mismo, tecnología, educación, sociedad, etc. Este esquema conceptual es capaz de recoger de forma general los diferentes filtros por los que ha de pasar el concepto de

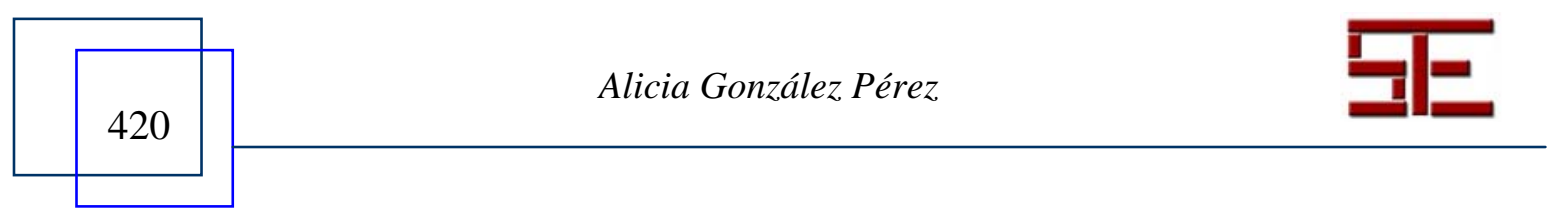




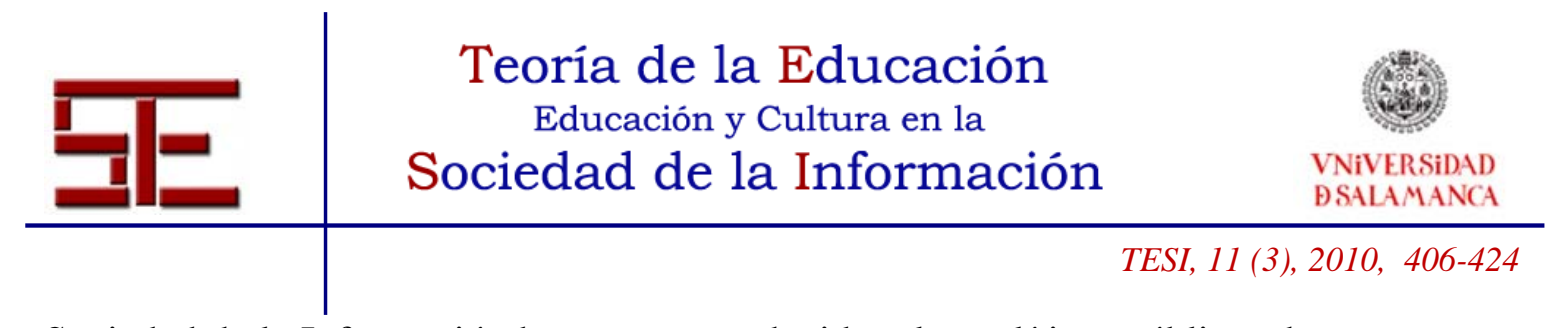

Sociedad de la Información hasta verse traducido a las políticas públicas de un contexto determinado, en este caso de Corea.

En realidad, el concepto de Sociedad de la Información se ha utilizado en la práctica como paraguas de una amplia variedad de ámbitos, incluyendo el desarrollo tecnológico e industria, la política económica, educativa y social, y la aplicación de las tecnologías por la propia administración. Como todos estos ámbitos son habitualmente objeto de políticas públicas, cuando no la justificación de la propia existencia e intervención de las administraciones públicas, resulta natural que éstas se hayan sentido llamadas a intervenir al respecto del desarrollo de la Sociedad de la Información ${ }^{8}$. Sin embargo, como reflejo de la inespecificidad del concepto, los programas públicos de la Sociedad de la Información en distintos entornos, incluso entre países con niveles de desarrollo económico y cultural similares, difieren mucho tanto en su planteamiento como en sus resultados. También los esquemas de organización adoptados por las administraciones para impulsar políticas que sirvan para desarrollar la Sociedad de la Información difieren mucho entre los distintos países. En ocasiones, esta tarea se ha adscrito directamente a los ministerios de mayor rango, como Economía, o incluso la propia Presidencia, mientras que en otros se ha relegado a los Ministerios con menor relevancia. En el caso de Corea con el fin de atender a las necesidades que planteaba la Sociedad de la Información se creó un departamento específico que se denominó Desarrollo de Recursos Humanos, que se adhirió al ya existente Ministerio de Educación. Actualmente, este Ministerio ha adquirido otra nomenclatura, Ministerio de Educación, Ciencia y Tecnología.

\section{5.- CONLUSIONES}

Las TIC en sí mismas no pueden desarrollar lo que conceptualmente entendemos Sociedad de la Información. Por ello, en el caso de Corea fue muy importante la implicación del gobierno y la elaboración de un marco legislativo potente que fomentara el uso de las TIC, no sólo en el ámbito educativo sino también en otros ámbitos sociales. El desarrollo de políticas de fomento de infraestructuras, que el Ministerio de Información y Comunicación (MIC) elaboró a mediados de los años noventa sería pieza clave para la creación de una sólida red de infraestructuras a lo largo y ancho del país, que proveería de banda ancha a todos los ciudadanos. Esto haría que todos los ciudadanos estuvieran conectados en una aldea global: Internet.

Hablar de sociedad de la información implica sin duda un grado de innovación tecnológica. En el caso de Corea la innovación tecnológica estuvo muy ligada a la reforma educativa que tuvo lugar a mediados de los 90. Esto provocó cambios

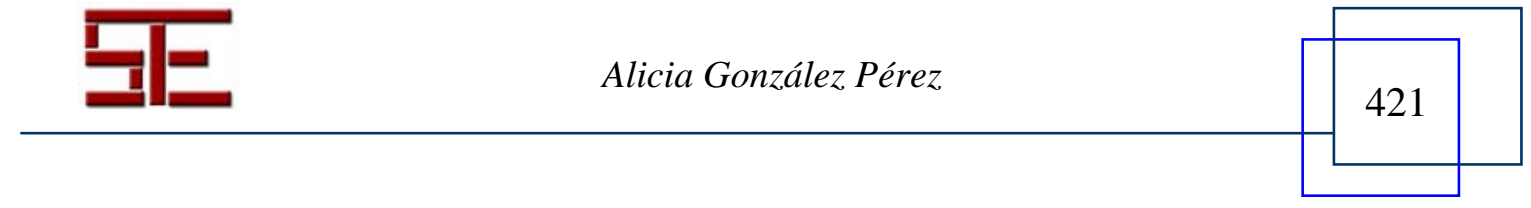




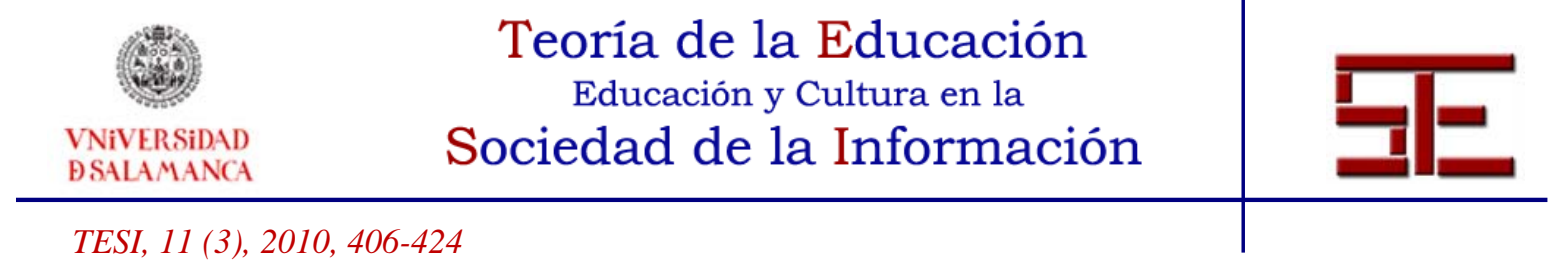

significativos en la organización escolar y la aparición de nuevas necesidades educativas que se concretaron en iniciativas, tales como: dotación de equipamiento y conexión de los centros, fomento de las TIC en la vida cotidiana y una legislación que promoviera el uso de las TIC en las distintas áreas sociales.

Pero no sólo se trató de crear una infraestructura tecnológica para el uso de las TIC en las escuelas sino también se trató de implementar el uso de las TIC como parte fundamental en el proyecto educativo de entro. Cuatro iniciativas fueron objetivo primordial en la Ley de Promoción de las TIC en las escuelas: desarrollo de contenidos educativos de calidad, implantación de programas de formación del profesorado, mejora de las infraestructuras tecnológicas y desarrollo de proyectos que analicen las consecuencias de la introducción de las TIC en la escuela.

Cabe destacar que la capacitación del profesorado en el uso de las TIC fue clave para introducir las TIC en la acción curricular y pensar en nuevas metodologías de enseñanza-aprendizaje que con la implantación del séptimo currículo nacional se estaban demandando.

\section{6.- BIBLIOGRAFÍA}

De Pablo Pons, J. (2007). La educación infantil y primaria en la sociedad del conocimiento: el aprendizaje mediado por las tecnologías de la información y la comunicación. En S. Romero Granados, Introducción temprana a las TIC: estrategias para educar en un uso responsable en educación infantil y primaria (pp. 25-43). Aulas de verano: MEC-Ediciones.

De Pablo Pons, J. (2006). Incorporación de las TIC en los centros de secundaria y bachillerato. Sevilla: Consejería de Educación, Ciencia y Tecnología.

De Pablo Pons, J. y González, T. (2007, marzo). Políticas educativas e innovación educativa apoyadas en TIC: Sus desarrollos en el ámbito autonómico. Ponencia presentada en las II Jornadas Internacionales sobre Políticas Educativas para la Sociedad del Conocimiento, Granada.

De Pablo Pons, J. y Jiménez Cortés, R. (2007). Buenas prácticas con TIC apoyadas en las Políticas Educativas: Claves conceptuales y derivaciones para la formación en competencias ECTS. Revista Relatec, vol. 6, (2), 15-28.

De Puelles Benítez, M. (2006). Problemas actuales de política educativa. Madrid: Morata.

FUNDACIÓN TELEFÓNICA (2007). Informe: La Sociedad de la Información en España. Ariel. Disponible http://www.telefonica.es/sociedaddelainformacion/.

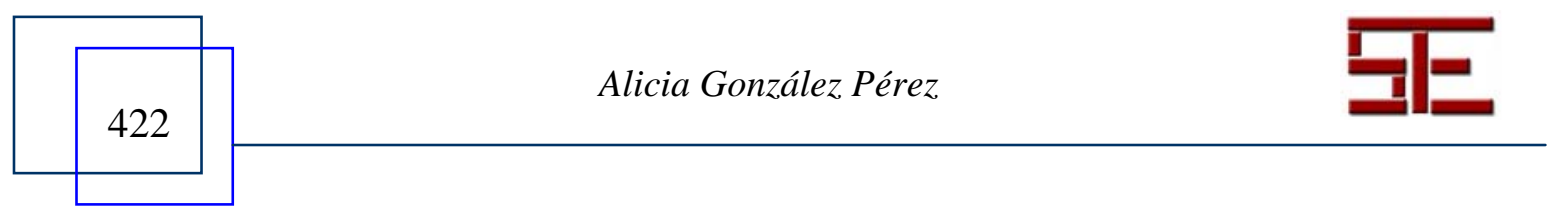




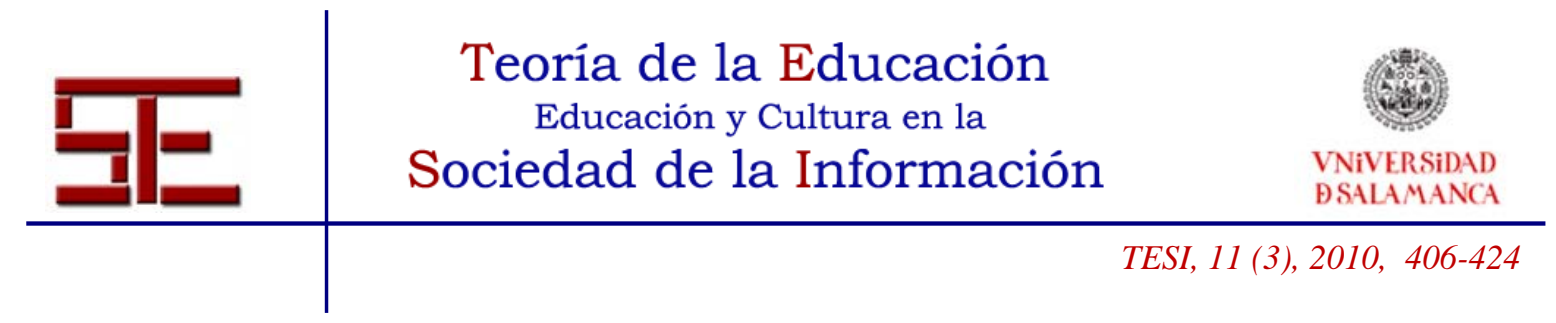

González Pérez, A. \& Kyoung Gun, H. (2007). E-accessibility through assistive technologies for people with disabilities in Spain inside European framework. Special Research Education Institute. Seoul, Korea: Ed. Dankook University. vol.18, 47-71.

INFORME BANGEMANN (1994). Europa y la sociedad global de la información: recomendaciones al Consejo Europeo. Disponible [on-line] http://biblio.uoc.es:443/docs_elec/2704.htm.

INNWOO PARK (2005). Cyber Home Learning System: Promise, Status and Future. The first APEC Future Education Forum, Busan, Korea.

INFORME DELORS (1996). La educación encierra un tesoro. Informe a la UNESCO de la Comisión Internacional sobre la educación para el siglo XXI. Madrid: Santillana, Ediciones UNESCO.

Iyanga Pendi, A. (2006). Política educativa: naturaleza, historia, dimensiones y componentes actuales. Valencia: Ed. Culturals Valencianes S.A.

Jeong Won, K. (2004). Education reform policies and classroom teaching in South Korea. International Studies in Sociology of Education, KEDI, vol. 14,(2), 125145.

KEDI (2007). Understanding Korean Education. Vol. 5 Education and Korea's Development. Korea. Disponible [on-line] http://eng.kedi.re.kr/09_edu/img/koredu/vol.\%205_\%20Education\%20and\%20 \%korea's\%20Development.pdf

MOE\&HRD \& KERIS (2005). Adapting Education to the Information Age. Republic of Korea.

- $\quad$ (2007). Adapting Education to the Information Age. Republic of Korea. ISBN 978-89-5984-239-1 93370.

OECD (2004). Education at a Glance. OECD Indicators 2004.

- $\quad$ (2007). Korea: Progress in Implementing Regulatory Reform. ISBN 978-92-6403205-7, 190 pp.

Ruiz de Querol, R. Análisis de la formación de las políticas de Sociedad de Información en Cataluña (1993-2003). Tesis doctoral dirigida por Dr. Manuel Castells Oliván. Universidad Oberta de Catalunya. Junio de 2006. Disponible [on-line] http://sociedaddelainformacion.telefonica.es/documentos/articulos/Analisis_for macion_politicas_SI_Catalunya.pdf.

Seth Michael, J. (2002). Education Fever: Society, Politics and the Pursuit of Schooling in South Korea. University of Hawai Press.

UNESCO (2005). Informe mundial de la UNESCO: Hacia las sociedades del conocimiento. Francia: Ed. UNESCO.

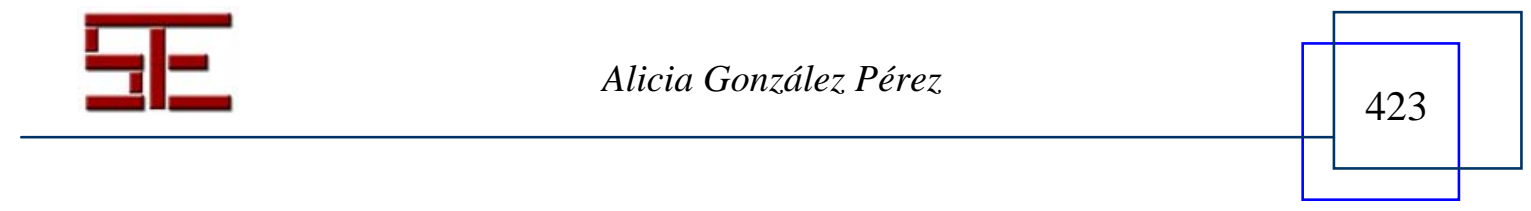




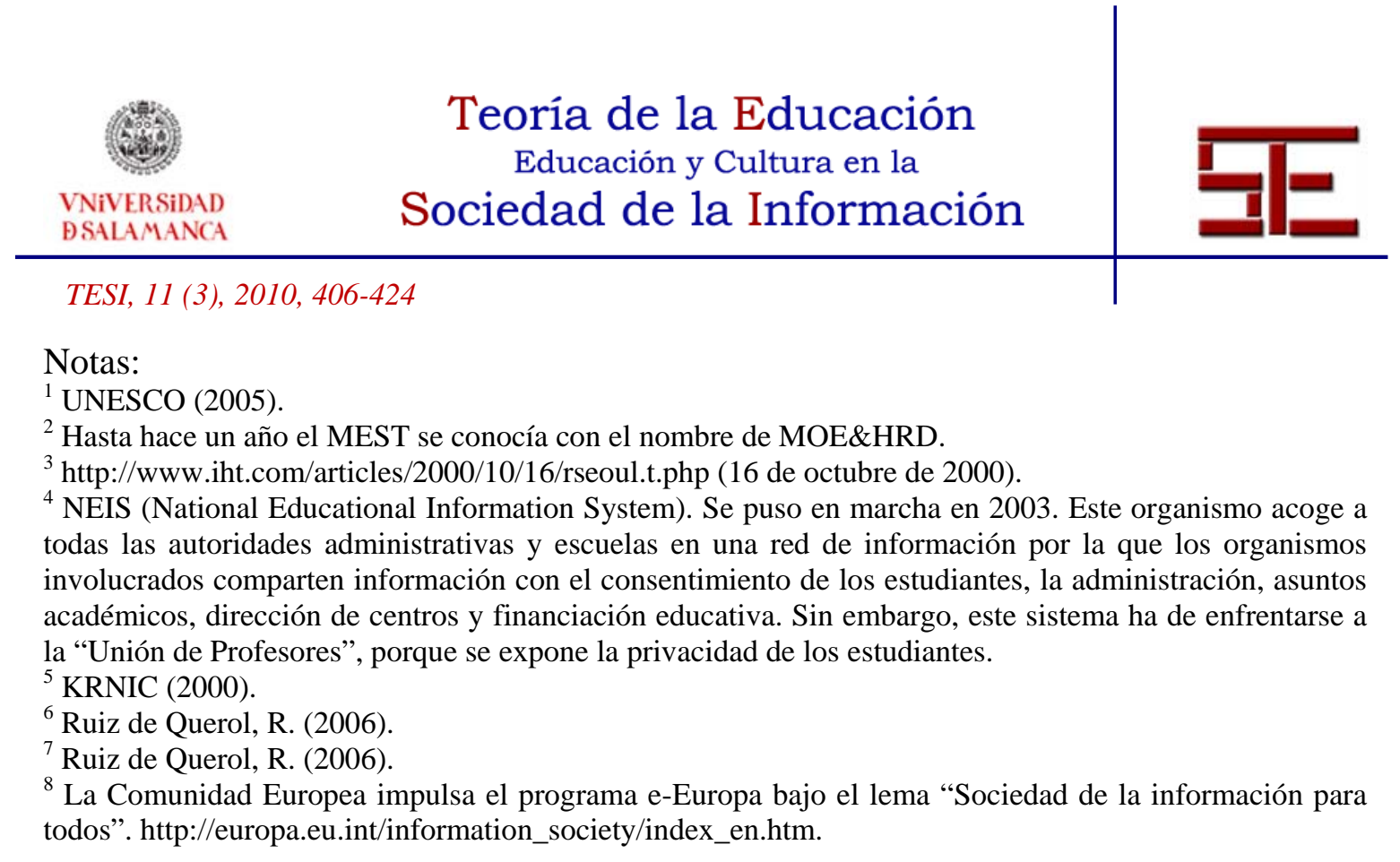

Para citar el presente artículo puede utilizar la siguiente referencia:

González Pérez, A.: (2010). "Políticas educativas públicas en Corea del Sur en la formación de la sociedad de la información”. En De Pablos Pons, J. (Coord.) Buenas prácticas de enseñanza con TIC [monográfico en línea]. Revista Electrónica Teoría de la Educación: Educación y Cultura en la Sociedad de la Información. Vol. 11, n ${ }^{0} 1$. Universidad de Salamanca, pp. 406-424. [Fecha de consulta: dd/mm/aaaa]. http://revistatesi.usal.es/ revistas_trabajo/index.php/revistatesi/article/view/6311/6326 ISSN: 1138-9737

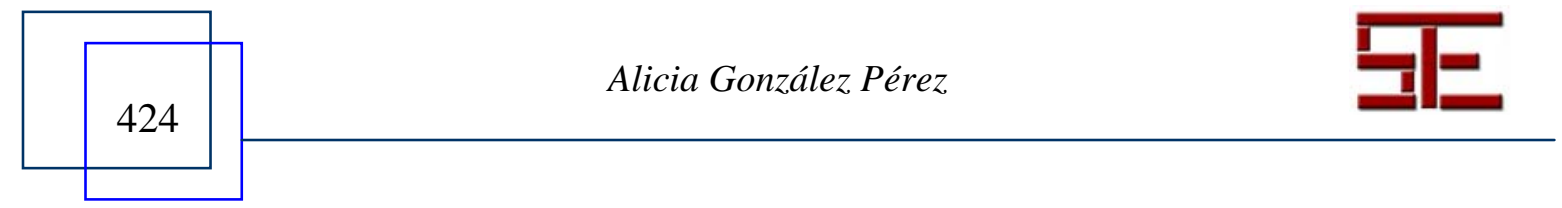

